\title{
Pulmonary hamartoma with low FDG uptake: A case report
}

\author{
Gulfidan Cakmak $^{1}$, Tuba Selcuk ${ }^{2,3}$, Yildiray Savas ${ }^{2}$ \\ 1. Department of Pulmonary Disease, Haseki Education and Research Hospital, Istanbul, Turkey. 2. Department of \\ Radiology, Haseki Education and Research Hospital, Istanbul, Turkey. 3. Department of Medical Sciences, Gelisim \\ University, Istanbul, Turkey.
}

Correspondence: Tuba Selcuk. Address: Department of Radiology, Haseki Education and Research Hospital, Istanbul, Turkey. Email: drtubas@gmail.com

Received: June 4, 2014

Accepted: July 7, 2014

Online Published: September 5, 2014

DOI : $10.5430 /$ crim.v2n1p7

URL: http://dx.doi.org/10.5430/crim.v2n1p7

\section{Abstract}

Introduction: Pulmonary hamartomas are the most common benign tumors of the lung. It usually shows no FDG uptake and has a low risk for malignant transformation. We present a rare case of pulmonary hamartoma with low Fluorodeoxyglucose uptake to call attention to the low malignancy potential of this benign tumor.

Case presentation: 67-year old male patient on the preoperative evaluation for his lumbar disc surgery was found out to have a solid lesion detected on chest computed tomography with low Fluorodeoxyglucose uptake.

Conclusion: Pulmonary hamartomas are benign tumors. But although their benignity they may show Fluorodeoxyglucose uptake and also they have a low risk for malignant transformation. So they should be followed up closely.

\section{Keywords}

Hamartoma, FDG uptake, Benign tumor

\section{Introduction}

Hamartoma is the most common benign tumor of the lung containing normal pulmonary tissue including bronchi, cartilage and fat ${ }^{[1]}$. It is mostly asymptomatic and show no FDG uptake on PET ${ }^{[1,2]}$. It is assumed to carry low risk for malignant transformation ${ }^{[3]}$. In addition; when diagnosed radiologically, hamartomas usually are being followed up clinically and radiologically. Because of increasing rates of reported cases on both low risk of malignant transformation and low FDG uptake of pulmonary hamartoma, with the presentation of that case we wanted to point out that although it is diagnosed radiologically as hamatoma, in patients above 40 years of age and with smoking history histopathological diagnosis should be advised for exclusion of malignancy.

\section{Case presentation}

A 67 year-old smoker male patient without any significant past medical history was consulted to the pulmonology clinic for preoperative evaluation of the lumbar disc surgery. On his physical examination there were widespread both inspiratory and expiratory rhonchi and coarse rales on right hemi thorax. He had 50 pack/year smoking history. When 
opacity was detected on his chest roentgenogram (see Figure 1) chest CT was performed. On chest CT a heterogeneous pleura based solid lesion with minimal lobulated margins was seen on the anterior segment of the upper lobe of the right lung and a $5 \mathrm{~mm}$ parenchymal nodule on the superior segment of the lower lobe of right lung (see Figure 2, 3). In accordance with these findings bronchoscopy and PET was performed to the patient. On PET a mass setting on the pleura with a broad base which has a lower FDG uptake (SUD max: 3-4) was detected (see Figure 4). Because of the lower FDG uptake a granuloma was suspected but tumors with a low mitotic activity couldn't be excluded. Because the patient couldn't tolerate, bronchoscopy with local anesthesia wasn't performed to the patient but TTFNAB was performed. In the pathology specimen taken by CT assisted TTFNAB with 18 G needle, fibromyxoid and fibrolipomatous fragments, chondroid material and epithelial cell groups were detected. These findings were compatible with hamartoma (see Figure 5).

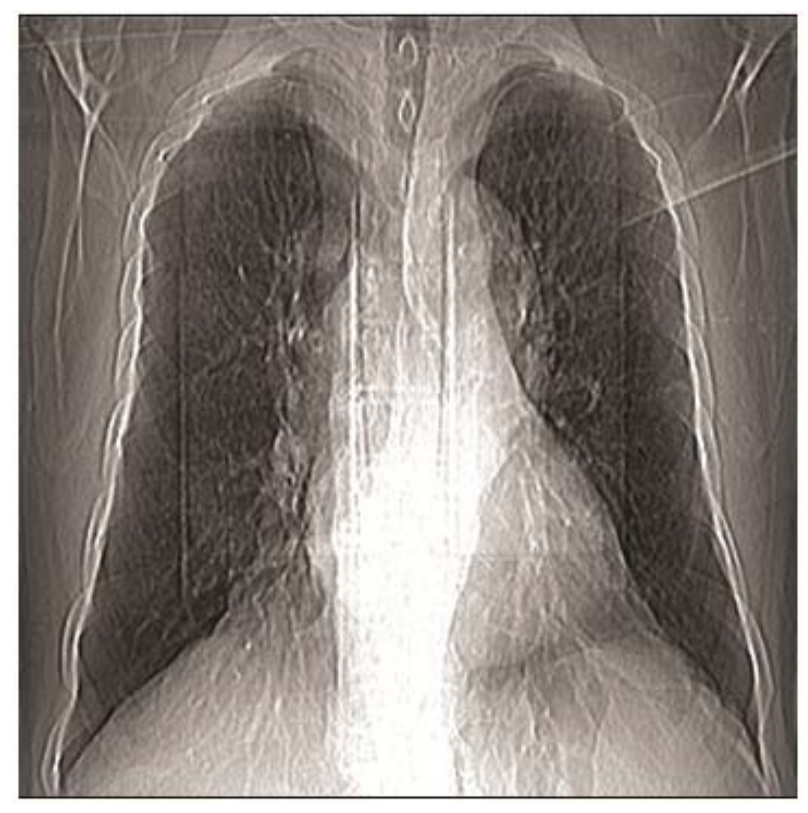

Figure 1. Chest Roentgenogram showing a nodular opacity in the right upper zone
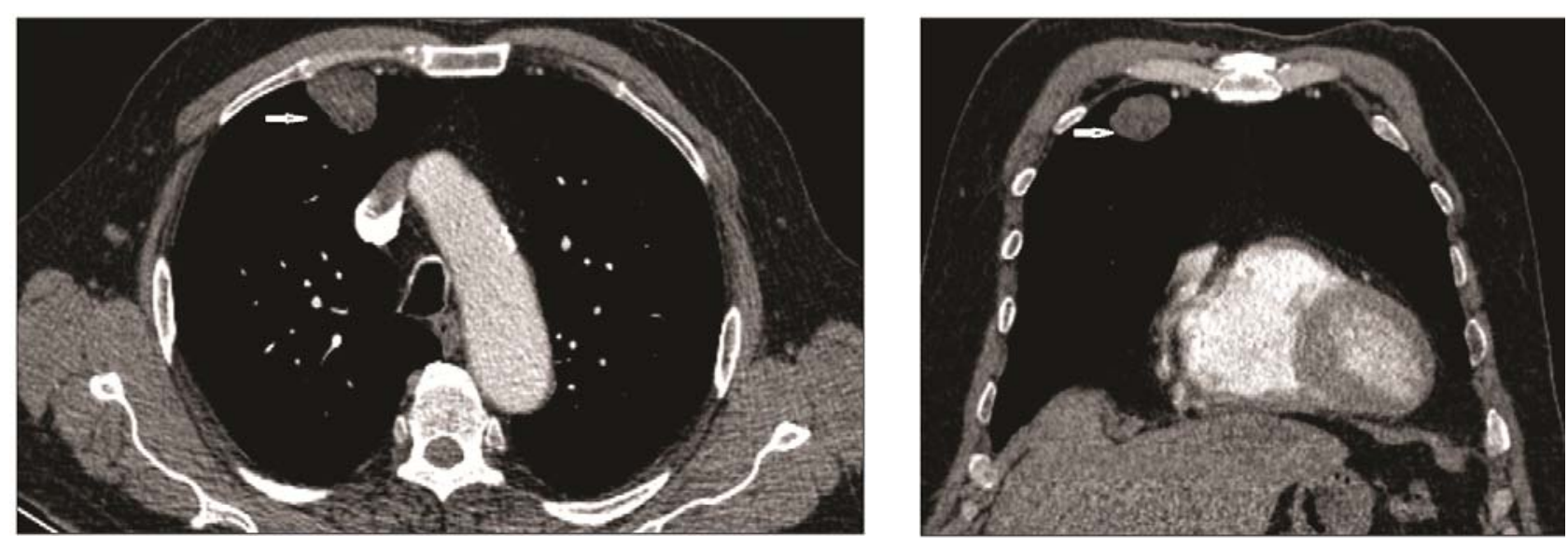

Figure 2, 3. Axial (Figure 2) and coronal (Figure 3) contrast enhanced chest CT images: A heterogeneous solid lesion setting on the pleura with a broad base was seen on the anterior segment of the upper lobe of the right lung. 


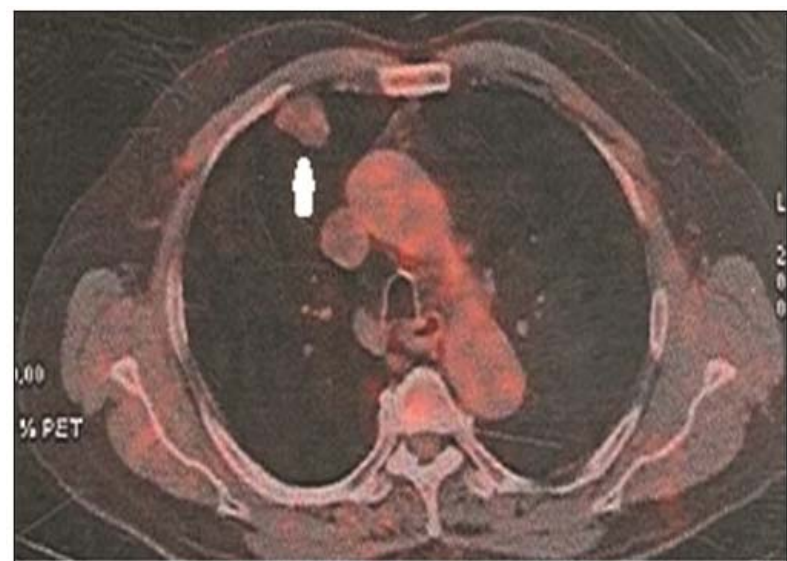

Figure 4. PET image showing FDG uptake

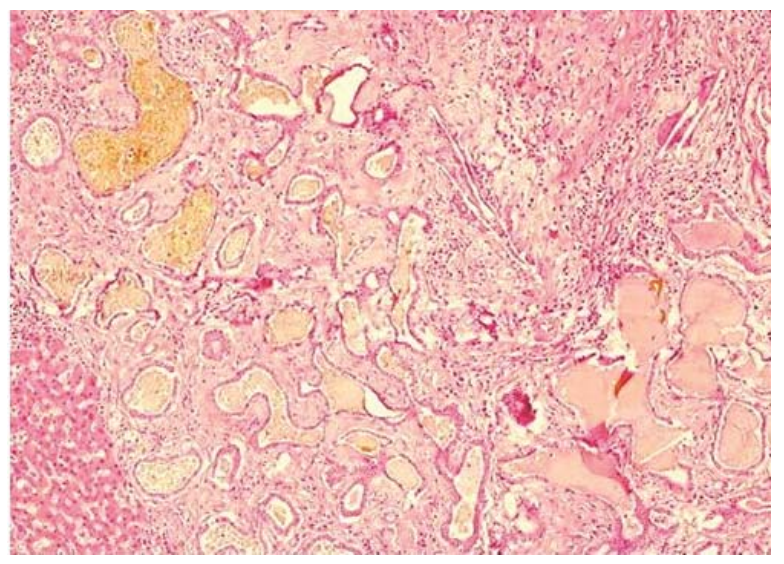

Figure 5. Pathology specimen: fibromyxoid and fibrolipomatous fragments, chondroid material and epithelial cell groups are seen

\section{Discussion}

Pulmonary hamartomas account for the $5 \%-8 \%$ of the all solitary pulmonary nodules and $75 \%$ of all benign lesions ${ }^{[4-6]}$. They are seen 30-60 years of ages and equally among men and women. In some publications factors like inflammatory lung disease and smoking were implied to contribute to the development of hamartomas. Because of this it was assumed to be seen in late decades and mostly among men ${ }^{[6,7]}$ as was so in our 67 year-old male patient. Mostly they are asymptomatic. They usually have a peripheral localization but when localized endobronchially they may cause dyspnea, wheezing and pneumonia ${ }^{[6,8]}$. Our case was also found incidentally on preoperative evaluation without causing any symptoms and was localized peripherally in the lung.

Hamartomas has mesenchymal origin ${ }^{[8,9]}$. They may consist of fat, epithelial, fibrous or chondroid tissues. Popcorn calcification may be seen in some cases ${ }^{[4,10,11]}$ which is a highly diagnostic feature when seen on chest CT but mostly CT findings are nonspecific as in our case that doesn't have the specific popcorn calcification.

The metabolic activity of the hamartoma tissue is close to the normal tissue and negativity is reported on PET ${ }^{[12-15]}$. Unlike this negativity there was a lower uptake in our case. In literature development of squamous cell carcinoma from hamartoma was reported ${ }^{[4]}$. Ribet et al. reported the prevalence of bronchial carcinoma in a 598 hamartoma series which was presented by nine different authors between the years of 1971 and 1992. This ratio is six times of the incidence of bronchial carcinoma in normal population ${ }^{[7]}$. In a series of 15 years of observation Karasik reported development of 6 bronchial carcinoma among 52 hamartoma patients and presented that out of these four had the same lobe localization as the hamartomas (2 synchronized, 2 metachronized) ${ }^{[16]}$. Akal et al. also reported the hamartoma and malignancy coexistence three times of the reported literature $(15.38 \%){ }^{[8]}$. In accordance with these in our case because of the suspicious uptake in PET histopathological diagnosis was made and there was no evidence of malignancy.

In peripheral hamartomas follow up and in centrally localized hamartomas excision is advised as management ${ }^{[4]}$. Agreeably to the literature; because of its being asymptomatic and having no evidence of malignancy in addition to its peripheral localization our patient is now under control with yearly clinical and radiological follow up.

\section{Conclusions}

As a result we advise also the close follow up of the hamartomas because of their malignancy potential and we emphasize that a more accurate diagnosis and follow up can be made by using PET in addition to chest CT. 


\section{References}

[1] Syed A, Suzanne L A, Nitra P, et al. False-Positive FDG Pozitron Emission Tomography Uptake in Nonmalignant Chest Abnormalities. AJR Am J Roentgenol. 2004; 182: 983-989. http://dx.doi.org/10.2214/ajr.182.4.1820983

[2] Oldham H N, Young W G, Sealy W C. Hamartoma of the lung. J ThoracCardiovasc Surg. 1967; 53: 735-742. PMid:6025818

[3] Christensen J A, Nathan M A, Mullan B P, et al. Characterization of the solitary pulmonary nodule: 18F-FDG PET versus nodule-enhancement CT. AJR Am J Roentgenol. 2006; 187: 1361-1367. http://dx.doi.org/10.2214/AJR.05.1166

[4] Basu S, Nandy S. Chondroidhamartoma presenting as solitary pulmonary nodule: Results of dual time point 18F-fluorodeoxyglucose-PET and comparison with 18F-fluorothymidine PET and histopathology. Hell J Nucl Med. 2011; 14(2): 173-4.

[5] De Cicco C, Bellomi M. Imaging of lung hamartomas by multidetector computed tomography and positron emission tomography. Ann Thorac Surg. 2008 Dec; 86(6): 1769-72. http://dx.doi.org/10.1016/j.athoracsur.2008.08.033

[6] Ulku R, Eren SN. A case of pulmonary hamartoma in interlobar fissure. Resp Dis. 2002; 13: 52-5(in Turkish).

[7] Ribet M, Jaillard-Thery S. Pulmonary Hamartoma and Malignancy. J Thorac Cardiovasc Surg. 1994; 107: 611-4. PMid:8302082

[8] Akal M, Cangır AK. Pulmonary hamartoma syndrome. Journal of Ankara Medical School. 1998; 51 (1): 27 -33(in Turkish).

[9] Diniz G, Ortac R. Chest wall hamartoma: Case Report. Ege Journal of Medicine. 2005; 44 (1): 55-8.

[10] Asad S, Aquino SL. False-Positive FDG Positron Emission Tomography Uptake in Nonmalignant Chest Abnormalities. AJR. 2004; 182: 983-89. http://dx.doi.org/10.2214/ajr.182.4.1820983

[11] Nicholas E, Braff S. Imaging Evaluation of the Solitary Pulmonary Nodule. Clinics in Chest Medicine. 2008; $29: 1$.

[12] Marotta G, Voltini F. FDG-PET and computed tomography in diagnosis of lung hamartoma. Nucl Med. $2010 ; 51$ (2): 1590.

[13] Souza FF, Chen E. Mesenchymal cystic hamartoma of the lung: MRI and PET/CT appearance. J Thorac Imaging. 2009 Feb; 24(1): 52-5. http://dx.doi.org/10.1097/RTI.0b013e31818c8834

[14] Park CM, Goo JM. Tumors in the tracheobronchial tree: CT and FDG PET features. Radiographics. 2009 Jan-Feb; $29(1)$ : 55-71. http://dx.doi.org/10.1148/rg.291085126

[15] Himpe U, Deroose CM. Unexpected slight fluorodeoxyglucose-uptake on positron emission tomography in a pulmonary hamartoma. J ThoracOncol. 2009 Jan; 4(1): 107-8. http://dx.doi.org/10.1097/JTO.0b013e31818e0e02

[16] Karasik A, Modan M. Increased Risk of Lung Cancer in Patients with Chondromatous Hamartoma. J Thorac Cardiovasc Surg. 1980; 80: 217-220. PMid:7401673 